\title{
A methodology for pre-selecting sustainable development indicators (SDIs) with application to surface mining operations
}

\author{
C. A. Poveda \\ Department of Mechanical Engineering, University of Alberta, Canada
}

\begin{abstract}
The creation of the World Commission on Environment and Development (WCED), commonly known as the Brundtland Commission, and the publication in 1987 of its report, "Our Common Future" marked a turning point towards finding the balance among society, economy, and environment. Since then, governments have improved existing regulations or created others, organizations for standardizations have developed new standards, management and process practices have addressed potential gaps, public and private organizations have taken initiative through the creation of committees and programs and research covering all areas of sustainable development has become a priority for academics and practitioners. These different sources serve as the basis for a pre-selection process of sustainable development indicators (SDIs). While some sources do not specifically address certain industries, the pre-selection process suggested in this manuscript studies and analyzes each SDI's resource and the possible applicability of already-identified indicators. An assertive set of SDIs is not solely based on regulatory systems, as measuring sustainability cannot become a bureaucratic process, and neither can any other SDI's source single-handedly determine or mandate the final set of indicators, as the real objective is to assist decision-makers and effectively engage stakeholders. This paper presents an analysis of six different sources for pre-selecting SDIs, accompanied by a methodology to then finalize with a set of SDIs for the surface mining operations in oil sands projects. Surface mining projects are complex operations with several social, economic, environmental, and health impacts. As the government and oil sands developers are turning towards increasing
\end{abstract}


productivity with a more conscious sustainable development approach, a preselection of SDIs is required to assist further formal multi-criteria selection processes.

Keywords: sustainable development, surface mining, energy consumption, oil sands, heavy oil, indicators, SDIs, sustainability assessment.

\section{Introduction: sustainable development indicators}

Local, regional, national, and international public and private organizations identify sustainability trends by using sustainable development indicators (SDIs), which are also frequently applied to measure the effectiveness and efficiency of sustainable development policies, businesses, and projects. The use of indicators facilitates the communication of positive and/or negative developments towards sustainability [1]. Moreover, the use of indicators and indices - which are a combination of indicators - prevails among other tools and methodologies to assess sustainable development; however, in sustainability indicators development, the selection and specification of the reference condition or start up point is crucial [2].

To design effective SDIs, the aspects of the essence of sustainability must be understood. These aspects include balanced development, equity and shared responsibility extended over time and space, and participation. An extensive debate has raged over the economic, social, and environmental aspects of sustainability and how to achieve the best balance between them. A variety of tools and methodologies have been developed, but as more tools become available, the deepness of the debate increases. Several questions challenge society, policy-makers, scientists, and stakeholders: What should and should not be measured? How should those be measured? Who should participate? The answers to these and many other questions may still be far from resolved; however, the participatory process in the achievement of sustainable development highly recommends the inclusion of stakeholders in determining what needs to be done and how [3]. It is contradictory to think of an effective stakeholder engagement in the development of sustainability indicators, as there is a weak involvement process of decision-makers in the initial setting of them, and an existing gap between the scientists or technically-oriented individuals and the decision-makers who dominate the socio-political arena. Furthermore, the process for selecting criteria and indicators demands transparency in the decision-making process and a methodology that differs from an ad hoc process, as these can lead to unwanted and unpopular decisions.

\section{Resources for pre-selecting sustainable development indicators}

Selecting SDIs offers a challenge for researchers and practitioners. The question of what should be measured or which SDIs should be included is crucial for effectively measuring sustainable development. An alternative that could be used before a formal set of SDIs can be implemented involves pre-selecting social, 
economic, and environmental indicators based on different resources presently used. Independently of directly referring to a certain process (e.g., surface mining) these resources offer a variety of SDIs that may indicate their usefulness based on proven performance. A pre-selected set of SDIs illustrates to decisionmakers a collection of possible indicators that they may have not initially considered in their sustainable development performance metrics.

\subsection{Governmental regulations}

Even though regulations do not guarantee the proper set of indicators to accomplish the objectives of sustainable development, regulatory-based indicators are relevant enough to be considered part of the path towards sustainable development. As stakeholders, the regulatory governmental agencies are part of the decision-making process, and are accountable for putting in place an appropriate set of rules to guarantee fairness, equality, and opportunity, and ensure operations are adjusted to current laws. In addition to having a key role in the decision-making process, government legislators are elected by the people and legislate on their behalf; the interests of the community take priority over those of an individual or selected group. Regulatory-based criteria put a certain amount of pressure on the government legislators to have the proper set of regulations in place. Furthermore, these regulations must be adjusted to the needs of the community and the requirements of the projects to which the regulations are directed.

As they cannot be considered the expected goal, governmental regulations set the starting point towards sustainable development, and are meant to be immersed in the sustainable development set of indicators. In fact, a series of criteria based solely on regulations does not guarantee sustainability, and instead creates a bureaucratic tool. Out of the three pillars of sustainability, the environment receives the strongest assistance from the regulatory bodies, while the social and economic aspects would be significantly weakened if they relied purely on regulations to set SDIs.

Environmental, economic, social, health, and political impacts of surface mining operations are evaluated by the national, provincial and/or local governments that have jurisdiction over each specific project. A report presented to the United Nations explains that regulations are designed to be applied during the life cycle of the mine, starting in the planning phase and continuing to the final closure and remediation; however, closure and remediation are two aspects not properly addressed during or after the course of the operations [4].

\subsection{Committees and organizations for standardization}

Standards are codes of best practices developed with the aim of improving safety, efficiency, interoperability, and trading [5]. Different organizations around the world are dedicated to identifying and developing what different markets and industries require. Even though organizations for standardization have recently focused on developing standards related to sustainable development, their main focus has been the building construction industry. 
Organizations for standardization can be found on the global, regional, and national scale. The International Organization for Standardization (ISO) has a strong global presence. Out of 205 countries in the world, 163 are represented in the ISO as one of three categories: member bodies, correspondent members, and subscriber members. The ISO's well-structured standards development process consists of six different stages - proposal, preparatory, committee, enquiry, approval, and publication - and requires committee members, who represent countries around the world, to reach agreements by consensus. This process makes the ISO a democratic organization interested in stakeholder involvement. At the regional level, the European Committee for Standardization (CEN) mostly comprises country members of the European Union, 28 of which are active members joined by the Former Yugoslav Republic of Macedonia, Turkey, Iceland, Norway, and Switzerland. In 1991, ISO and CEN signed the Vienna agreement, with the aim of avoiding duplication of standards between both bodies. Since then, CEN has adopted several ISO standards. Among different national organizations for standardization, the British Standard Institution (BSI) and the Canadian Standard Association (CSA) have active roles in the production of standards and the supply of standards-related services.

\subsection{Management and processes best practices}

Different industries use the concept of best management practices (BMPs) to measure operational and management performance. Different processes and procedures are part of the set of guidelines in the production of a product and/or service [6]. BMPs can be developed by government agencies, industry associations, focus groups, and temporary partnerships, among others, or embedded in management systems or standards. BMPs are set as guidelines for organizations and practitioners to improve their performance; however, environmental and governmental regulations may mandate the minimum requirements (i.e., monitoring, inspections, design requirements, water effluents, air emissions, etc.). Sustainable BMPs embedded in corporate management programs give organizations a competitive advantage.

Best practices in management and processes may not have deep impacts on the functionality of the organization, as standards or management systems; though this enhances the flexibility characteristic of BMPs. Moreover, when applied to a specific industry such as mining, setting up BMPs is crucial in order to meet sustainability goals and objectives. BMPs are meant to be flexible so they can meet varying requirements, such as types of mining operations, climate, surrounding environment, topography, social demands, and stakeholder expectations. In fact, local governments with jurisdiction over mining projects have developed guidelines for BMPs throughout the mining project life cycle. However, the main opportunities to reduce impacts of mining operations are in the planning and design phase, rather than during operation or post-closure [7]. Nevertheless, sustainability principles are focused in each phase of a project's life cycle and do not act in isolation [8].

BMPs not only include engineered and technical aspects; management, project management processes, innovation, and safety are among other areas that 
impact the overall performance of mining projects and contribute to meeting the sustainable development objectives. BMPs in management include effective communication of the mission and strategy, leadership by example, setting realistic targets, communication of management style, and clear and careful strategic planning, among others. However, mining companies are not always are driven by reason to improve. Instead, external factors - such as competitive market pressures, new market opportunities, regulatory pressures, and the 'voice of society' - force them to include innovation as part of the corporate management strategy to remain competitive. Society, employers, government, and employees can participate in the innovation process, in areas such as safety. Cooperation between employers and employees in implementing safety practices and minimizing hazard exposure is part of the success in the area of safety in surface mining operations.

\subsection{Surface mining industry standards and programs}

Standards define a series of benchmarks expected to be followed. Differentiation is made based on the resource of the standards: governmental or statutory standards enforced by law (e.g., regulations) are different from proprietary standards developed by firms and organizations, which in turn differ from voluntary standards established by consultation and consensus for use by their respective industry, organization, or individual. Voluntary standards are not legally binding and are expected to be enforced by the members of each particular association. The standards referred to in this section are voluntary standards the mining industry has adopted toward accomplishing the goals and objectives of sustainable development and minimizing the different impacts (i.e., social, economic, environmental, health) the mining operations intrinsically carry in each phase of the projects. Industry occasionally relies on outside resources to set up their standards (e.g., ISO, CEN, and BSI); in other instances, collaborative work is part of their agenda toward specific programs.

Mining practices may vary from project to project due to geographic location and external factors as a consequence of particular environmental, social, economic, or geo-political conditions. Mining organizations (e.g., associations, institutes) around the world adopt standards that meet the needs of regional mining operations. Though certain standards applied in European mining operations may apply in other projects that are geographically different, the worldwide benchmarking of mining operations and the industry's sustainable development performance have proven to be challenges that the industry has yet to overcome. Therefore, national or regional associations become a key performance factor for the industry.

An essential standard for the mining industry involves the reporting of mineral resources and reserves. Though at first, most may think the crucial aspect of reporting does not connect with sustainable development, the reality is that mineral resources have an impact on the commodity wealth of countries; attract political attention; and affect financial, accounting, and investment communities [9]. Therefore, economic, social, and political aspects of sustainable development may be impacted by the different objectives and 
outcomes of reporting systems. Similar to other industry standards, international and national mining organizations have released standards and guidelines for classifying, valuing, and reporting mineral resources and reserves [9]. As sustainable development criteria are identified for each stage of the projects, the reporting systems are included as management criteria for the sustainability of mining operations. In addition to standards, mining industry organizations engage in programs and initiatives for a number of reasons, including research, benchmarking, and development, among others. The program or initiative goals are usually mandated by the needs of the industry and its members. In the case of sustainable development, the mining industry is requested to align with international, national, and local governmental mandates, attend to the different needs of stakeholders, and/or increase productivity with more efficient and effective processes.

\subsection{Local, regional, national, and international organizations}

A number of non-governmental (NGOs) and intergovernmental (IGOs) organizations work toward developing, monitoring, interpreting, and communicating sustainable indicators frameworks. As the interest in sustainable development increases, organizations such as the United Nations (UN) and its agencies have focused their attention on creating a comprehensive set of indicators to monitor and measure progress toward overall societal well-being. These indicators address social, economic, environmental, institutional, and policy-related aspects, among other aspects of sustainability. The UN is not acting alone in this challenging effort; local, regional, national, and other international organizations have also acted, either by adapting the UN framework of indicators or developing their own.

With the premise of forming a solid foundation for decision-making, Charter 40 of Agenda 21 urges countries (i.e., the national level) and international, governmental, and non-governmental organizations to identify and develop SDIs. In 1995, the Commission on Sustainable Development (CSD) approved its Work Programme on Indicators of Sustainable Development. The latest set of SDIs came as a response to the CSD and the World Summit on Sustainable Development in 2002. Additionally, the United Nation, in its report "Indicators for Monitoring the Millennium Development Goals," presents what have become known as the eight Millennium Development Goals (MDG). Different World Summits and conferences have helped to shape the Millennium Development goals and indicators. Each goal includes time-bound targets, and different indicators are linked to each target.

Instead of using a global framework of indicators, region-specific organizations focus on developing frameworks to meet local social, economic, and environmental needs. In the EU system, Eurostat, a directorate-general of the European Commission, and the European Environmental Agency (EEA) specify that sustainable development indicators (SDIs) "are to be developed at the appropriate level of detail to ensure proper assessment of the situation with regard to each particular challenge" [10]. 
Global organizations such as World Resources Institute (WRI) believe in the efficacy of indicators as agents of change: they can simplify and quantify information while improving communication between different decision-makers. Working with government, companies, and civil society, the WRI builds solutions to urgent environmental challenges. Instead of giving a set of indicators, the WRI proposes an explicit conceptual model to guide the development of environmental indicators. Similarly, rather than developing the 'ideal' set of indicators to assess sustainable development, the International Institute for Sustainable Development (IISD) concentrates its efforts on identifying principles to link theory and practice.

In 1994, the UK Government launched its Strategy for Sustainable Development, following the commitment made at the Earth Summit in 1992. Similarly, the Canadian Government has also developed a series on environmental sustainability indicators; similarly, a variety of initiatives in the public and private sector are in place, either at the national or local scale. Although one of the largest surface mining operations is located in the province of Alberta, Canada, the projects lack a project-specific framework of indicators to measure sustainability performance. However, the Pembina Institute, also located in the province, developed a 51-indicator framework through the Alberta Genuine Progress Indicator (GPI) project. As the province leading the country in setting publicly-reported indicators to track progress, Alberta uses a series of initiatives to measure the total societal well-being. The GPI consists of 51 indicators including social, economic, and environmental aspects. Sustainable Calgary developed a 36-indicator framework to measure well-being within its borders, and documented its findings in its "State of Our City" report.

\subsection{Academically - and scientifically - authored resources}

Nowadays, the focus of academics and researchers includes every aspect of sustainability, as the area has become a leading interest for the primary stakeholder of public and private projects: society. Instead, thoughtful analysis and preselecting methodologies are highly recommended without isolating a specific ecosystem, project, or industry; in fact, Fricker [11] describes how sustainability goes beyond measuring and monitoring economic, social, and environmental conditions, as the term 'sustainability' also refers to ecological integrity, quality of life, and transformation or transcendence. An integration of all aspects of sustainability is needed to decisively assert the set of SDIs. Although Hilson and Basu [12] make reference to the lack of a credible attempt to develop a framework of SDIs suitable for application at the corporate level of the mining industry, after the Earth Summit in Rio in 1992, the debate around the applicability of sustainability principles in mining operations (exploration, operation, and closure stages) has exponentially increased.

The spectrum of sets of SDIs for each industry sector is an overwhelming resource for the pre-selection process: indicators for major infrastructure projects, legacy mine land, coal mining operations, and forest management are a sample of the SDIs set through research that can assist the SDIs pre-selection process for surface mining operations. Additionally, the research on SDIs brings 
different and more detailed perspectives by studying a single resource, such as energy; a sole dimension of sustainability; a specific ecosystem (e.g., river basins); or sustainability from the corporate standpoint. Finally, in the SDIs identification process, the three main pillars of sustainability must be balanced amongst themselves in the final set of SDIs, while taking into account the influence of corporate sustainability, including corporate social responsibility (CSR), stakeholder theory, and accountability and transparency.

Research on sustainable mining is found around the world. Regional research groups (funded by the private or public sectors, or both) concentrate on finding the best practices to minimize the different impacts intrinsically found in mining operations. Although, independently of where the mining operations occur, the mining industry is actively engaged in sustainability through research, development, and innovation, the mining and minerals industry faces several challenges on its road to sustainability.

\section{Pre-selection process methodology}

The six resources for the pre-selection of SDIs are organized in three distinctive groups (as shown in Table 1). Grouping the different resources into three types of originators has an impact on determining the indicators' participation in the final set of pre-selected SDIs for surface mining operations.

Table 1: Grouping Sustainable Development Indicators resources.

\begin{tabular}{|c|c|c|c|c|c|}
\hline \multicolumn{6}{|c|}{ Group originator of SDIs } \\
\hline \multicolumn{2}{|c|}{$\begin{array}{c}\text { Indicators agreed on by public } \\
\text { or governmental representatives } \\
\text { through consensus }\end{array}$} & \multicolumn{2}{|c|}{$\begin{array}{l}\text { Indicators identified by academics } \\
\text { and practitioners }\end{array}$} & \multicolumn{2}{|c|}{$\begin{array}{c}\text { Indicators established by } \\
\text { organizations }\end{array}$} \\
\hline $\begin{array}{l}\text { Govern- } \\
\text { mental } \\
\text { regulations }\end{array}$ & $\begin{array}{l}\text { Committees } \\
\text { and } \\
\text { organizations } \\
\text { for standardi- } \\
\quad \text { zation }\end{array}$ & $\begin{array}{l}\text { Management } \\
\text { and processes } \\
\text { best practices }\end{array}$ & $\begin{array}{l}\text { Academically- } \\
\text { and scientifically } \\
\text {-authored } \\
\text { resources }\end{array}$ & $\begin{array}{l}\text { Local, regional, } \\
\text { national, and } \\
\text { international } \\
\text { organizations }\end{array}$ & $\begin{array}{l}\text { Surface mining } \\
\text { industry } \\
\text { standards and } \\
\text { programs }\end{array}$ \\
\hline \multicolumn{6}{|c|}{ Available resources for SDI identification } \\
\hline
\end{tabular}

The pre-selection process begins (as shown in Figure 1), with a raw list of indicators identified after an in-depth analysis of the different resources available for SDIs. The applicability and origin of each indicator is then determined. Even though the raw list of indicators may contain a large number of indicators, this initial screening process questioning the applicability of the indicators to surface mining operations serves to limit that number. As a final step, the indicators are organized according to the resource of origin. As expected, indicators may show their origins from multiple resources.

To determine the inclusion of an indicator on the pre-selected list of SDIs, certain criteria must be met, or a minimum number of points must be accumulated. At this point, the indicators are initially screened and categorized, 
and their origins are identified (independently of having indicators in multiple categories, as they can be found in different resources). All indicators in the list are assigned one point before a close scrutiny occurs to select the final set of preselected SDIs. Six is the maximum number of points an indicator can accumulate.

As there is a range of scores ( 1 to 6 points) possible for each indicator, it is necessary to carry out an analysis of each score and the criteria of inclusion in the pre-selected set of SDIs:

- Score of 6 or 5 points: These indicators are implied to be part of the final set of pre-selected SDIs, as it is understood by the number of points that they come from different resources and from all group originators of SDIs.

- Score of 4 points: Three scenarios are identified: (1) an indicator present in all three group originators of SDIs would automatically make it part of the final set; (2) an indicator coming from only two group originators of SDIs, as long as one of those is the indicator reached through consensus by public or governmental representatives, would be included as part of the final set, as it is supported by governmental regulations; and (3) an indicator coming from two group originators of SDIs (indicators identified by academics and practitioners or established by organizations) would require further analysis to determine its inclusion in the final set. Among others, this analysis would address the indicator's usefulness and applicability, decision-makers' and stakeholders' considerations, and the goals and objectives of sustainable development.

- Score of 3 points: Three scenarios similar to those under the 4-point score are identified. Therefore, the selection criteria are consistently applied. A fourth scenario may be possible: the indicator includes one point in its score because it comes from the indicators reached through consensus by public or governmental representatives, but particularly from the committees and organizations for standardizations. In this case, the indicator needs further analysis.

- Score of 2 points: The indicator is present in one or two group originators of SDIs. An indicator present in two group originators is stronger. In any case, further analysis is needed. Indicators collecting one point because they are from the governmental regulations resource are included in the pre-selected SDIs final set.

- Score of 1 point: This is the "weakest" of all cases. Only indicators from the governmental regulations resources are directly included in the final set of pre-selected SDIs; others require further analysis.

Far from being a bureaucratic process because of the inclusion of indicators from the governmental regulations resource, the purpose of the pre-selected methodology is to point out the need for stringent regulations and more governmental participation in sustainable development on behalf of stakeholders 


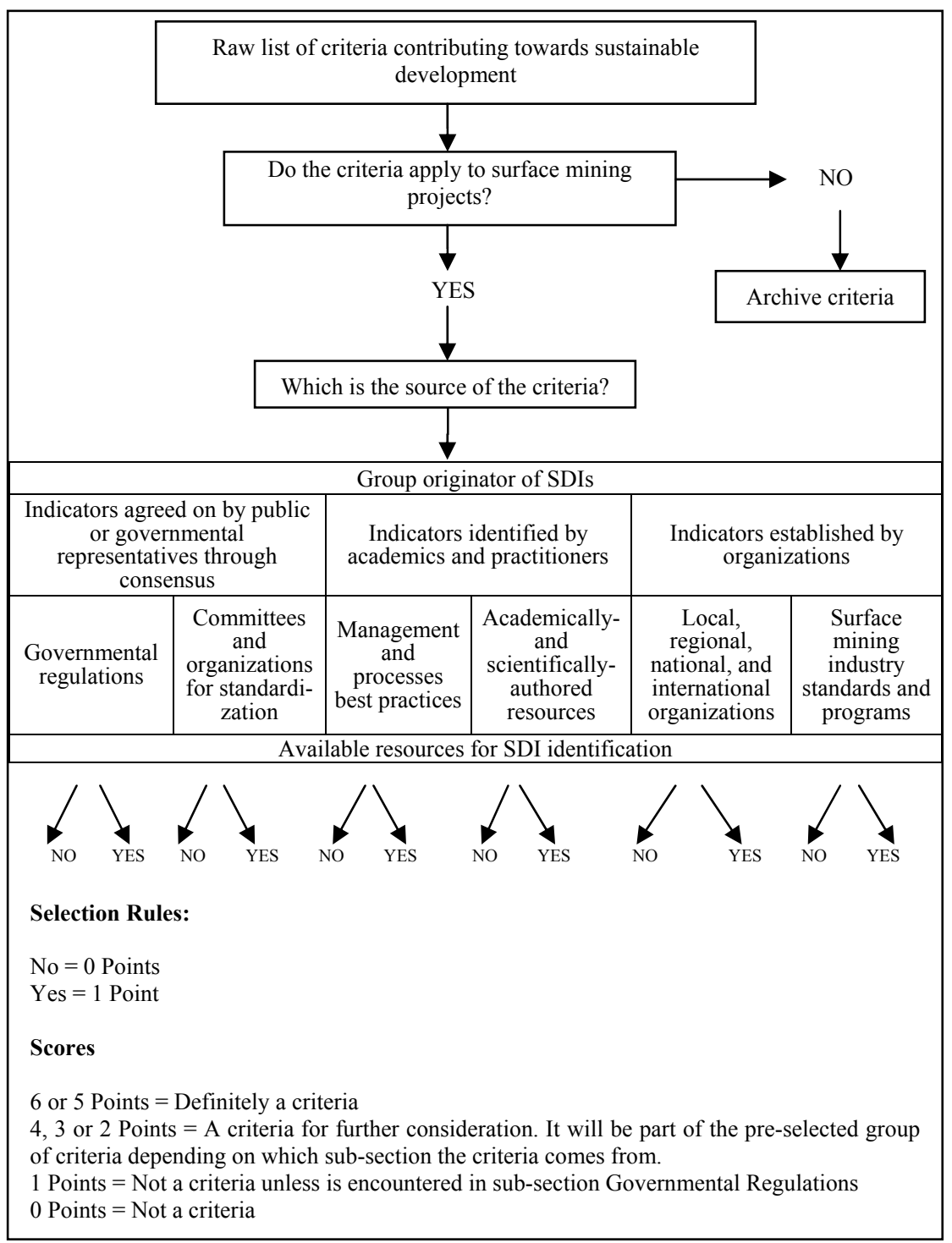

Figure 1: Flow diagram to pre-select indicators.

and citizens. This pre-selection methodology offers the critical advantage of having considered indicators from all ends of the spectrum. The final set is left to decision-makers and stakeholders, as it is determined through further multicriteria decision-making processes or any other methodology available and selected by the practitioner or researcher. 


\section{Conclusions and future research}

If the intricacy of identifying and measuring impacts, the complexity of the projects, and stakeholders' expectations are added to the fact that sustainable development itself is still evolving, practitioners and researchers must somehow find the starting point to pre-select potential SDIs to measure the sustainability of the projects. Therefore, the aim of the pre-selection methodology and the different resources available for SDIs identification presented in this paper is to assist and increase confidence in the preliminary efforts towards a formal multicriteria decision-making process.

A primary obstacle in pre-selection methodologies arises because of the lack of SDIs in certain resources for specific projects (i.e., committees and organizations for standardization have not developed any guidelines for SDIs for surface mining operations); as a result, indicators' applicability and stakeholder expectations become a priority in the pre-selection process. Another two main issues prevail in selecting a set of indicators and benchmarking the overall sustainability indicator: (1) each community, business, or project has unique needs; and (2) it is difficult to place some indicators in a specific category. Additionally, the narrow idea of associating sustainability to just the environmental pillar of sustainable development is still present; consequently, there is a need to assist stakeholders and practitioners in general with broadening any pre-conceived idea of sustainable development by presenting a large set of pre-screened SDIs that is still diverse enough to give stakeholders the opportunity they had been calling for to provide input in the participatory decision-making process.

The question of what should be measured is not fully answered, but rather, is emphasized; while researchers and practitioners continue looking for agreement on it, the next step is to try to answer how to measure the diverse number of existing SDIs found in different resources. The sustainability of surface mining operations can be measured independently; however, they contribute to the overall oil sands projects' sustainable development performance. Therefore, the pre-selection process is a preliminary effort before not only choosing the final set of indicators, but also deciding how to express all indicators in a similar measuring scale (i.e., all indicators expressed in money, time, or any other selected unit of measure). Individually, each indicator can be expressed in a different unit, although the overall sustainable development performance must be narrowed into a single assessment value.

\section{References}

[1] European Commission. (2001). Measuring progress towards a more sustainable Europe: Proposed indicators for sustainable development. Office for Official Publications of the European Communities: Luxembourg. 
[2] Gilbert, A. (1996). Criteria for sustainability in the development of indicators for sustainable development. Chemosphere, 33(9), pp. 1739-1748.

[3] Guy, G. B. \& Kibert, C. J. (1998). Developing Indicators of Sustainability: US Experience. Building research and Information, 26(1), pp. 39-45.

[4] United Nations. (Undated). National reporting to CSD-18/19 - Thematic Profile on Mining. http://www.un.org/esa/dsd/dsd_aofw_ni/ni_pdfs/ NationalReports/canada/Mining.pdf.

[5] BSI. British Standard Institution. (2012). What we do. http://www.bsigroup.com/en/Standards-and-Publications/About-BSIBritish-Standards/What-we-do/.

[6] Szwilski, T. B. (2007). Using Environmental Management Systems to Systematically Improve Operational Performance and Environmental Protection. International Journal of Surface Mining, Reclamation and Environment. 14(3), pp. 183-1991.

[7] Stewart, M. \& Petrie, J. (2007). Planning for Waste Management and Disposal in Minerals Processing Using Life Cycle Assessment. Min Energy Raw Mater Rep. 14(3), pp. 14-36.

[8] McLellan, B. C., Corder, G. D., Giurco, D. \& Green, S. (2009). Incorporating Sustainable Development in the Design of Mineral Processing Operations: Review and Analysis of Current Approaches. Journal of Cleaner Production, 17, pp. 1414-1425.

[9] Weatherstone, N. (2008). International Standards for Reporting of Minerals Resources and Reserves - Status, Outlook and Important Issues. World Mining Congress \& Expo 2008, Krakow, Poland.

[10] European Commission (2009). Sustainable Development Indicators: Overview of relevant FP-funded research and identification of further needs. European Communities: Luxembourg.

[11] Fricker, A. (1998). Measuring Up to Sustainability. Futures, 30 (4), pp. 367-375.

[12] Hilson, G. \& Basu, A. (2003). Devising Indicators of Sustainable Development for the Mining and Minerals Industry: An Analysis of Critical Background Issues. International Journal of Sustainable Development \& World Ecology, 10 (4), pp. 319-331. 